\title{
COLONIALIDADE, MULHER INDÍGENA E VIOLÊNCIA: REFLEXÕES CONTEMPORÂNEAS
}

\author{
Thaís Janaina Wenczenovicz ${ }^{1}$ \\ Rodrigo Espiuca dos Anjos Siqueira ${ }^{2}$
}

\section{RESUMO:}

Para compreender a violência contra os Povos Indígenas no Brasil contemporâneo, faz-se necessário partir de uma análise sistêmica e de longa duração, considerando a trajetória histórica de vulnerabilização desses grupos. Em se tratando da mulher indígena a situação é mais grave. Em um contexto de defesa de territórios e exclusões sociais, as mulheres indígenas têm sido alvo de violências baseadas em gênero, a exemplo dos feminicídios, da exploração sexual, do tráfico de pessoas e das agressões de outras naturezas que se acentuam na medida em que elas afirmam o seu protagonismo político em defesa dos seus povos e seus direitos.

Palavras-chave: Colonialidade; Comunidades Indígenas; MulheresViolência

\section{COLONIALITY, INDIGENOUS WOMEN AND VIOLENCE: CONTEMPORARY REFLEXIONS}

\begin{abstract}
:
In order to understand violence against Indigenous Peoples in contemporary Brazil, it is necessary to start from a systemic and long-term analysis, considering the historical trajectory of vulnerability of these groups. When it comes to indigenous women, the situation is even more serious. In a context of the defense of territories and social exclusion, indigenous women have been subjected to perverse gender-based violence, such as feminicide, sexual exploitation, persons trafficking and aggression of other natures, which are accentuated as they affirm their political protagonism in defense of their peoples and their rights.
\end{abstract}

Keywords: Coloniality; Indigenous Communities; WomenViolence

\section{INTRODUÇÃO}

Impossível analisar a história da América Latina sem levar em consideração a presença das comunidades indígenas. Assentados em dezenas de etnias e com matrizes

\footnotetext{
${ }^{1}$ Docente adjunta e pesquisador sênior na Universidade Estadual do Rio Grande do Sul. Professora colaboradora no Programa de Pós-Graduação em Educação da Universidade estadual do Paraná/UNIOESTE e em Direitos Fundamentais da Universidade do Oeste de Santa Catarina/UNOESC.

${ }_{2}^{2}$ Professor na Faculdade Anglicana de Erechim e Discente no Doutorado do Programa de Pós-Graduação em Direito na Universidade Federal do Rio Grande do Sul/UFRGS.
} 
linguísticas e costumes diferenciados denotam sua singularidade na composição sóciohistórica da maioria dos países latino-americanos. ${ }^{3}$

Concomitante a sua historicidade acompanham sua trajetória constante a luta pela sobrevivência frente à violência desencadeada pelo colonizador. Um dos maiores desafios que a América Latina enfrenta na busca pela igualdade é a inclusão dos direitos dos povos indígenas entre as prioridades enquanto políticas públicas. Inúmeros são os desafios, pois vivem na América Latina mais de 800 povos indígenas, com uma população próxima de 45 milhões e, se caracterizam por sua ampla diversidade cultural, demográfica, política, social e territorial - incluindo os povos em isolamento voluntário até a presença marcante nas áreas e assentamentos urbanos.

Em grande parte da América Latina constata-se o quadro de omissão dos poderes públicos na efetivação dos Direitos Humanos e Fundamentais as comunidades indígenas, que associada à demora na demarcação, proteção e fiscalização das terras corroboram com a minimização cultural, resultando em violência estrutural, fome, pobreza extrema e doenças incluindo morte prematura de crianças indígenas por falta de assistência médica adequada. A falta de saneamento básico, associada à falta de água potável também estão entre as demandas de diversos países na tentativa de diminuir a violência às populações indígenas.

Acrescenta-se ao contexto, o percurso da história dos povos indígenas na América Latina, marcado por diferentes processos e formas de injustiça e violências institucionalizadas. Inicia pela negação da sua cultura, transita em longo tempo pela negação da trajetória histórica e chega aos dias de hoje marcado pelo limite ao exercício de direitos e, consequentemente, de cidadania.

Em se tratando de mulher indígena a situação torna-se ainda mais grave e acompanha a história desse grupo humano em diversos países. As mulheres são as principais vítimas da violência praticada contra a população indígena no mundo. As indígenas são citadas pelas estatísticas como aquelas que têm mais chance de serem violentadas fisicamente do que outras mulheres, segundo o relatório da Organização das Nações Unidas (ONU) divulgado em 2010.

\footnotetext{
${ }^{3}$ Para esse processo de análise faz-se necessário compreender a violência a partir da Colonialidade do Poder. Nesse artigo utiliza-se o conceito proposto pelo sociólogo peruano Aníbal Quijano e Zaffaroni, Raúl em El Derecho latinoamericano en la fase superior del Colonialismo.
} 
Também esse contexto, encontra-se o racismo, as doenças e a fome. Nessa direção pode-se apontar também o não acesso ao direito à educação, a terra e aos recursos econômicos.

O devido artigo divide-se em três partes. A primeira aborda elementos da trajetória histórico-política e social das comunidades indígenas na América Latina. A segunda traça elementos acerca do conceito de violência e seus desdobramentos nas comunidades indígenas em relação à mulher. Na terceira e última parte são apresentados bases e dados estatísticos que envolvem as comunidades indígenas, especialmente no aspecto a violência contra mulher.

Enquanto procedimento metodológico utiliza-se do método bibliográficoinvestigativo, acompanhado de documentos jurídicos como a Convenção $n^{\circ} 169$ sobre Povos Indígenas e Tribais em Países Independentes da Organização Internacional do Trabalho (OIT, 1989), ratificada pelo Brasil por meio do Decreto nº143 de 25 de julho de 2002; a Declaração das Organizações Unidas sobre os Direitos dos Povos Indígenas (ONU, 2007); a Convenção sobre a Proteção e Promoção da Diversidade das Expressões Culturais da UNESCO, ratificada pelo Congresso Nacional em dezembro de 2006, e promulgada no país pelo Decreto-Lei $n^{\circ}$ 6.177, de $1^{\circ}$ de agosto de 2007; a Convenção para a Salvaguarda do Patrimônio Cultural Imaterial, ratificada pelo Decreto $\mathrm{n}^{\circ}$ 5.753, de 12 de abril de 2006; cartas e decretos da Comissão de Direitos Humanos e Minorias (CDHM) e a Constituição do Brasil de 1988. Para a comparação de dados e bases estatísticas emprega-se os indicadores da Comissão Econômica para a América Latina e o Caribe (CEPAL), do Instituto Brasileiro de Geografia e Estatística (IBGE) e o relatório Violência Contra os Povos Indígenas no Brasil Dados de 2015, publicado pelo Conselho Indigenista Missionário (Cimi).

\section{COMUNIDADES INDÍGENAS NA AMÉRICA LATINA}

Por muito tempo as comunidades indígenas na América Latina foram vistas como um entrave ao desenvolvimento econômico, político e sociocultural. Assolados por doenças, perda de seus territórios e procedidos do processo de aculturação, assimilação e represamento herdaram imagens que se consolidaram com assento na violência física e simbólica e se popularizaram no imaginário contemporâneo.

Nesse contexto, cumpre-se indicar que há um componente comum: a quase extinção do povo indígena latino-americano seja ela física ou etnocultural. No primeiro caso, a população indígena, predominante na região nos tempos da colonização, hoje representa cerca 
de $10 \%$ da população latino-americana. Encontra-se concentrada principalmente em cinco países: Bolívia, Equador, Guatemala, México e Peru. No segundo caso, os índios latinoamericanos passaram por um processo de aculturação tão significativo que dificilmente podese falar hoje de etnias e culturas indígenas autênticas. Muito se perdeu de sua identidade com a eliminação de tribos inteiras e com a assimilação da cultura do colonizador.

A esse respeito, Lander (2006, p. 250) diz:

Ao fazer abstração da natureza dos recursos, espaço e territórios, o desenvolvimento histórico da sociedade moderna e do capitalismo aparece como um processo interno, autogerado, da sociedade europeia, que posteriormente se expande para as regiões atrasadas. Nessa construção eurocêntrica desaparece do campo de visão o colonialismo como dimensão constitutiva destas experiências históricas.

Quijano (1997) cunhou o conceito de colonialidade como algo que transcende as particularidades do colonialismo histórico e que não desaparece com a independência ou descolonização. Essa formulação é uma tentativa de explicar a modernidade como um processo intrinsecamente vinculado à experiência colonial. Essa distinção entre colonialidade e colonialismo permite, portanto, explicar a continuidade das formas coloniais de dominação, mesmo após o fim das administrações coloniais, além de demonstrar que essas estruturas de poder e subordinação passaram a ser reproduzidas pelos mecanismos do sistema-mundo capitalista colonial-moderno. Dessa maneira, a noção de colonialidade atrela o processo de colonização das Américas à constituição da economia-mundo capitalista, concebendo ambos como partes integrantes de um mesmo processo histórico iniciado no século XVI (CASTROGOMEZ; GOSFROGUEL, 2007).

Considerando que todo Estado Nacional se constrói a partir da criação de uma identidade étnica única através da língua oficial, do modo de produção econômico, dentre outros, a construção das hierarquias raciais, de gênero e de modos de apropriação dos recursos naturais, pode ser vista como simultânea e contemporânea à constituição de uma divisão internacional do trabalho e dos territórios, marcada por relações assimétricas entre economias desenvolvidas, em desenvolvimento e periféricas.

Aldao Y Clerigo (2011) complementam: 
identidades y de transferencia de sus tierras actúa conjuntamente para seguir produciendo desigualdad. Para remediarla, se requiere que las exigencias de reconocimiento cultural se integren con las pretensiones de redistribución socioeconómica. Padecen tanto la mala distribución socioeconómica como el erróneo y/o insuficiente reconocimiento cultural, sin que pueda entenderse que alguna de estas injusticias es un efecto indirecto de la otra. Por eso, ni las soluciones redistributivas ni las soluciones de reconocimiento son suficientes por sí mismas. Es decir, sólo son respetuosas de los derechos de los pueblos originarios aquellas soluciones que implican una mejor distribución de los bienes económicos y sociales, pero que a su vez, los incluyan en el proceso de toma de decisiones y se tenga en cuenta su interpretación de sus necesidades, intereses y proyectos como comunidade.

Nesse contexto, o desafio de se analisar a violência contra mulher na América Latina pelo viés das comunidades indígenas passa necessariamente pela superação do modelo cognitivo baseado no regime civilizatório, tendo em vista que um regime civilizatório é "muito mais que um modo de produção", posto que dá sentido ao mundo e confere autoridade à regulação estatal da vida coletiva.

Em virtude da exploração colonial, as comunidades indígenas perderam suas terras, seus costumes próprios, suas tradições milenares - fonte de sua sobrevivência. Isso acarretou uma piora significativa da sua condição de vida, colocando-os em uma severa condição de pobreza. Em alguns países, como no Brasil, o Estado demarcou reservas indígenas em todo o território nacional, na tentativa de lhes garantir a subsistência. Entretanto, as ações não foram decisivas na estagnação dos índices de violência. A título de exemplo pode-se citar a incidência de 52 casos com 54 vítimas de assassinatos nos Estados do Acre, Amapá, Amazonas, Bahia, Maranhão, Mato Grosso do Sul, Minas Gerais, Pará, Paraná, Pernambuco, Rondônia, Roraima, e Tocantins. (CIMI: Relatório Violência contra os Povos Indígenas no Brasil, 2016. p. 79)

Nessa cenário, Guha (1997) afirma que subalternidade não é somente uma questão de subordinação de classe dentro de um país industrial, mas de subordinação de organizações sociais e históricas no interior de estruturas interestatais, como as que se estabeleceram entre Índia e Inglaterra. Para o autor, o colonialismo britânico se caracterizou pelo exercício de uma dominação sem hegemonia, uma composição seriamente determinada pela dissolução dos elementos de persuasão e cooperação, que se ancoravam na força despótica da superioridade ocidental para erigir uma dominação política que aniquila o surgimento do dissenso ou conflito. Por outro lado, se poderia argumentar que as estratégias de colonização portuguesa e 
espanhola nas Américas parecem sugerir outro itinerário, que contemplaria uma fase do uso da força, com aniquilamento dos diferentes, alinhavada, em seguida, por processos de persuasão e cooperação que possibilitaram a construção de uma dominação hegemônica.

Em consonância ao relatório da Comissão Econômica para a América Latina e Caribe, um dos maiores desafios que a região enfrenta em sua busca pela igualdade é a inclusão dos direitos dos povos indígenas entre as prioridades das políticas. Os desafios são enormes, se considerarmos que na América Latina, como se examina neste estudo, existem centenas de povos indígenas, com uma população próxima de 45 milhões, que se caracterizam por sua ampla diversidade demográfica, social, territorial e política, desde povos em isolamento voluntário $^{4}$ até sua presença em grandes assentamentos urbanos. A isto se acrescenta que o crescimento econômico registrado na região é altamente dependente dos recursos naturais e de seus preços internacionais, enquanto se observa uma governança deficiente destes recursos. A reprimarização da economia provocou fortes pressões sobre os territórios dos povos indígenas e desencadeou numerosos conflitos socioambientais ainda não resolvidos. (CEPAL, 2015. p. 6).

Diversos estudos apontam para um renascimento das comunidades indígenas, nas últimas duas décadas do século passado como resultado de ações coletivas e o enfrentamento ao poder das elites econômicas. A emergência dos povos indígenas como contestadores do modelo do Estado Nacional, enquanto monoétnico e monocivilizatório, especialmente a partir do levante zapatista em Chiapas/México, colocam na pauta de discussão a necessidade de autonomia política dos povos, bem como a necessidade de mudança na estrutura cognitiva e política do Estado. (LINEIRA, 2010, p. 161).

A trajetória de luta dos povos indígenas pela defesa e reconhecimento de seus direitos foi contínua e persistente na construção da história dos países latino-americanos. Este legado de reivindicação e reconhecimento ganhou espaço em um quadro de direitos que se fundamenta em dois grandes marcos: o Convênio sobre Povos Indígenas e Tribais de 1989

\footnotetext{
${ }^{4}$ Em levantamento que vem sendo realizado pelo Conselho Indigenista Missionário (Cimi) desde 2006, com atualização anual, foram identificadas 91 referências de grupos de indígenas sem contato no Brasil. A Fundação Nacional do Índio (Funai) considera 107 registros da presença de indígenas isolados em toda a Amazônia Legal. Muitos deles vivem em situação de risco devido à construção de megaempreendimentos de infraestrutura, como transporte, energia e comunicação, e à exploração ilegal realizada por madeireiros, fazendeiros e garimpeiros, que invadem e esgotam seus territórios ancestrais. Por serem extremamente vulneráveis, os povos denominados de isolados necessitam de atenção especial e políticas que assegurem efetivamente suas vidas e garantam a proteção de seus territórios. (CIMI, 2016. p. 152)
} 
(Núm. 169) da OIT, que reconhece pela primeira vez seus direitos coletivos, e a Declaração das Nações Unidas sobre os Direitos dos Povos Indígenas (2007), que propõe o direito desses povos à livre determinação. Por sua vez, o padrão mínimo de direitos dos povos indígenas, obrigatório para os Estados, articula-se em cinco dimensões: o direito à não discriminação; o direito ao desenvolvimento e bem-estar social; o direito à integridade cultural; o direito à propriedade, uso, controle e acesso às terras, territórios e recursos naturais; e o direito à participação política.

Em âmbito internacional existem dois mecanismos diretos de proteção dos direitos humanos, incluindo os direitos dos povos indígenas: o sistema das Nações Unidas e o Sistema Interamericano de Direitos Humanos da Organização dos Estados Americanos (OEA). Neste último, as sentenças da Corte Interamericana de Direitos Humanos, que têm caráter vinculante para os Estados, foram relevantes no novo ordenamento jurídico internacional no tocante aos direitos dos povos indígenas. No caso das Nações Unidas, os órgãos e mecanismos de proteção adquirem uma indiscutível relevância política para o reconhecimento e aplicação dos direitos dos povos indígenas.

Nesse cenário, S. James Anaya colabora dizendo que:

El sistema internacional contemporáneo reconoce abiertamente ahora que es un imperativo de derechos humanos el dar respuesta a las demandas de los pueblos indígenas. [...]. Sea como sea, lo cierto es que puede hablarse ahora de un régimen de derechos indígenas dentro del derecho internacional de los derechos humanos; un régimen todavia em desarrollo y que, en certa medida, beneficia a los pueblos indígenas. (ANYA: 2004, p. 30)

De uma forma objetiva, existem no sistema universal de proteção dos direitos humanos das Nações Unidas: a) mecanismos baseados na Carta das Nações Unidas, como o Conselho de Direitos Humanos, os procedimentos especiais, o exame periódico universal e órgãos assessores (como o Mecanismo de Peritos sobre os Direitos dos Povos Indígenas); b) mecanismos baseados na aplicação dos principais tratados vinculantes do direito internacional sobre os direitos humanos por parte dos países que os ratificaram. Geralmente os mecanismos que também são denominados 'comitês', há presença de especialistas. No aspecto acessibilidade, há diversas possibilidades para apresentar registros ao Conselho de Direitos 
Humanos, aos comitês e aos procedimentos especiais, garantindo assim o acesso ao sistema em casos de demandas emergenciais e urgentes.

Entretanto, há muito que se evoluir quando se analisa a questão indígena na América Latina. Sabe-se que o patrimônio indígena é composto pela terra em sua dimensão territorial e em seus usos de acordo com as normas e os costumes das sociedades nativas e, nesse aspecto há necessidade de avanço, pois estando distantes da terra ou alijados do direito de uso a violência tangencia todas as comunidades indígenas.

\section{MULHER INDÍGENA E VIOLÊNCIA(S): REFLEXÕES PONTUAIS}

As mulheres indígenas têm sido vitimadas por ações violentas no contexto de suas próprias sociedades, enquanto contato inter-tribal e, naquele imposto a partir do colonialismo europeu. A violência tem assumido formas diversas, dentre as quais a silenciosa/psicológica e a física. A violência praticada contra a mulher indígena realiza-se tanto em termos interpessoais como sociais e étnicos, principalmente nos embates do cotidiano ocorrendo de forma continuada, tornando-se naturalizada em diversos espaços e grupos sociais. Dentre as formas de violência direta estão o assassinato, a tentativa de assassinato, o homicídio culposo, a ameaça de morte e outras variadas formas de ameaças, as lesões corporais dolosas, o abuso de poder, o racismo, a discriminação étnico-cultural e a violência sexual.

A título de exemplo pode-se citar de acordo com os índices apresentados pelo Conselho Indigenista Missionário as mais de cinco dezenas de assassinatos ${ }^{5}$ de indígenas nos mais variados estados brasileiros no ano de 2015. Das 54 vítimas, oito eram do sexo feminino e tinham idades entre 9 e 82 anos. Uma criança do sexo feminino, de 9 anos, está entre as vítimas. As outras 46 pessoas, do sexo masculino, tinham idade entre 2 e 75 anos. Do total de vítimas, incluindo homens e mulheres, nove eram menores, e tinham idade entre 2 e 17 anos (CIMI, 2015, p. 79)

\footnotetext{
${ }^{5}$ Os casos de assassinato estão relacionados em sua maioria a questão de demarcação de terras. Das 1.113 terras indígenas reconhecidas, em processo de reconhecimento pelo Estado brasileiro ou reivindicadas pelas comunidades, até agosto de 2016, apenas 398, ou 35,7\%, tinham seus processos administrativos finalizados, ou seja, foram registradas pela União. (CIMI, 2016)
} 
A violência contra as comunidades indígenas, em sua maioria corresponde a questões de demarcações territoriais, ${ }^{6}$ ataques sobre os territórios, invasões, desmatamento, destruição de patrimônio, exploração ilegal de recursos naturais, contaminação de nascentes e rios, queimadas e incêndios, caça ilegal, e contaminação por agrotóxico, dentre outras ações que atingem as terras indígenas.

Soma-se a esse contexto, a desumanização, a escravização, os aldeamentos com as perdas territoriais, a depreciação semântica generalizante e a tentativa de redução linguística constituíram formas políticas violentas de negação das diferenças e práticas históricas de invisibilidade. Isso é o que Boaventura de Sousa Santos (2003, p.57) denomina de conhecimento-regulação, característico da ciência e do pensar modernos.

Outra forma de violência vivenciada pelas comunidades indígenas é a tentativa de assassinato. O Conselho Indigenista Missionário registrou em 2015, 31 casos de tentativas de assassinato. As ocorrências foram registradas nos estados de Alagoas (1), Amazonas (2), Maranhão (7), Mato Grosso (3), Mato Grosso do Sul (12), Minas Gerais (1), Pará (1), Paraná 2), Rio Grande do Sul (1) e Santa Catarina (1).

Geralmente as tentativas de assassinatos também estão relacionadas aos conflitos territoriais. Em sua maioria, os ataques contra as comunidades foram realizados por homens fortemente armados e com facilidade de ingresso nas terras indígenas por conhecerem a região e possuir bons meios de locomoção. Apesar das denúncias e dos pedidos de proteção aos órgãos de segurança nacional e estatal, os conflitos e as práticas de violência são constantes. Já os organismos protetores das comunidades indígenas, como a Funai - através de seus servidores - declaram-se impotentes diante das negativas a esses pedidos de ajuda.

No tocante a tentativa de assassinato, diversos são os casos que envolvem crianças e mulheres. Dentre os exemplos pode-se citar uma ação que ocorreu no Estado de Mato Grosso. Trata-se da etnia Bororo usuária da terra indígena Jarudori, localizada no município de Poxoréu. A tentativa de assassinato ocorreu na Porteira da aldeia indígena e teve como causa a ação de envenenamento tendo como meio empregado a ameaça à vida. $\mathrm{O}$ fato ocorreu no

\footnotetext{
${ }^{6}$ Segundo o Conselho Indigenista Missionário, a morosidade na demarcação das terras reforçam o sentimento de abandono do Estado para com as comunidades afetadas. Pode-se citar o caso da Terra Indígena (TI) São Gabriel/São Salvador, do povo Kokama, localizada no município de Santo Antônio do Içá, no Amazonas, que teve seu Grupo Técnico criado em 25 de abril de 2003, mas doze anos depois, seus trabalhos ainda não foram concluídos.
} 
local onde as crianças aguardam o ônibus escolar, na área indígena e foi denunciada em uma reunião entre a Funai $^{7}$ e o Ministério Público federal/MPF-MT. A FUNAI averiguou e constatou que os peixes envenenados foram deixados, por uma pessoa não identificada, perto da porteira da aldeia. No levantamento realizado pelo MPF nenhuma criança se alimentou dos peixes, mas cinco cachorros da aldeia, além de animais silvestres, morreram com suspeita de intoxicação. O MPF acionou a Polícia Federal para a apuração dos fatos. (CIMI, 2015, p. 93)

Submetidas a um processo de dupla-vitimização em suas próprias sociedades, vítimas das ações violentas de estranhos e pessoas de sua convivência, as mulheres indígenas viram as fileiras de seus agressores serem aumentadas com o passar dos anos. As ações de violência acompanham a trajetória histórica das mulheres indígenas, já que desde o processo de ocupação e povoamento essas são expostas a processos coletivos de desumanização de toda ordem. Acrescenta-se também o fato de reproduzirem a inferioridade social e política das mulheres na conjuntura local, bem como a ação constante do ideário do patriarcado nas áreas coloniais $^{8}$ e neocoloniais, onde continuam a vitimá-las.

Há quem argumente que a violência nas comunidades contemporâneas atingiu tal grau de perversidade que naturalizou-se, mas independentemente da validade ou não de tal premissa, fundamental mesmo é a compreensão da extensão e gravidade desse fenômeno social. Não há como omitir que desde muito a violência permeia grande parte das relações sociais, tendo, portanto, a mesma, passado por um processo de banalização. Por um lado, a sua concretização adentra e se efetiva nas comunidades indígenas permeada de uma série de questionamentos acerca da linha entre o que é e o que não é violência.

Também é possível reconhecer a presença de ameaças variadas no cotidiano feminino nas terras indígenas. Dentre elas pode-se citar: assédio moral e sexual, exploração de indígenas como "trabalhadoras sexuais", lesão corporal, sedução e estupro, estupro e atentado violento ao pudor, rapto e estupro, agressão causada por investigação de paternidade e

\footnotetext{
${ }^{7}$ Fundação Nacional do Índio.

${ }^{8}$ A cultura patriarcal vigente na América Colonial era indulgente para com maridos que infringiam castigos físicos a suas esposas. Marta Zambrano, em seu trabalho sobre os indígenas de Santa Fé de Bogotá entre a segunda metade do século XVI e a primeira do XVII, escreve que, quando esposos agressores eram processados judicialmente, recorriam a essa cultura. Sua defesa objetivamente envolvia a alegação de que agiram com violência por não terem sido obedecidos por "suas" mulheres. Os casos analisados pela autora não apontam para exceções, mas para o fato de que a violência era um elemento muito presente nas relações conjugais, oficiais ou não. (ZAMBRANO, 2008).
} 
tentativas de estupro. Em tais situações a violência contra as mulheres indígenas assume um caráter específico e até icônico.

De acordo com o líder Marcos Terena, articulador do Comitê Intertribal - Memória e Ciência Indígena (ITC), o estupro é uma forma de desmoralizar as comunidades e também uma espécie de limpeza étnica. O Relatório ONU Brasil acrescenta:

\begin{abstract}
A forma mais fácil de destruir um povo é desmoralizá-lo. Atingir a parte mais vulnerável do grupo tem esse objetivo. O racismo contra os indígenas é apontado como fator de violência e, em sua forma mais extrema, a discriminação pode levar a graves violações, como homicídio e estupro. Este tipo de discriminação é difícil de quantificar e verificar porque, ou não é documentado, ou não desagrega por etnia. Além de violência física, as mulheres indígenas também são alvo indireto de conflitos armados ou de desastres naturais. Por causa desses problemas, muitas vezes, ficam sem acesso à educação, à terra e a recursos econômicos, embora "sejam responsáveis pelos cuidados de saúde e bem-estar de sua família e comunidade. Estudos também revelam que as mulheres indígenas lideram os índices de mortalidade materna. Assim como a população indígena, em geral, "experimenta níveis desproporcionais" de mortalidade infantil, desnutrição, doenças cardiovasculares, Aids, além de outras doenças infecciosas como malária e tuberculose. (RELATÓRIO ONU BRASIL, 2015)
\end{abstract}

Como já apontado, nesse e em outros exemplos ser uma mulher indígena significa viver em uma condição de extrema fragilidade social. Para além da discussão sobre a exposição da maioria das mulheres indígenas a situações adversas relaciona-se a uma conjuntura histórica de colonialidade, ${ }^{9}$ já que aos olhos do colonizador, a mulheres indígenas eram marcadas por sua perversidade sexual. Sendo esses corpos perversos, automaticamente são considerados sexualmente violáveis e "estupráveis", e o estupro de corpos considerados inerentemente impuros ou perversos simplesmente não conta.

Existe toda uma teia social de poder e violência a ser estudada. Sabe-se que o ingresso da mão-de-obra da mulher indígenas no mercado de trabalho em função da expropriação das terras e o processo de aculturação deixou-as mais vulneráveis a todo e qualquer tipo de agressão, especialmente quando inseridas nas áreas urbanas - grandes cidades.

\footnotetext{
${ }^{9} \mathrm{Em}$ contraste com a forte natureza patriarcal das sociedades europeias antes da colonização, as sociedades indígenas, em sua maioria, não eram dominadas pelos homens. As mulheres atuavam como líderes espirituais, políticas e militares, e muitas sociedades eram matrilineares. Mesmo havendo uma divisão de tarefas entre homens e mulheres, ao trabalho da mulher e ao trabalho do homem era concedido o mesmo status. Como os homens e as mulheres vivam em harmonia, as sociedades indígenas eram, por consequência, muito menos autoritárias que suas correlatas europeias. (ANNETTE; HALSEY, 1992)
} 
Em muitos casos as mulheres indígenas foram condenadas, estigmatizadas e prejudicadas ao adentrarem no mercado laboral, pois as normas locais e étnicas legitimam a discriminação contra as mulheres, servindo primariamente para reforçar a subordinação das mulheres aos homens.

Segundo o relatório de Comissão Pastoral da Terra/Brasil (2015), mesmo atingindo, indiscriminadamente, famílias inteiras, os conflitos no campo têm alcançado diretamente as mulheres. Seja pela ascensão protagonista nas lutas, seja por apoiarem e continuarem a batalhada antes travada por marido e filhos, muitas vezes já mortos em ações de violência, as mulheres representaram três, dos 34 assassinatos registrados. Em uma retrospectiva, nos últimos dez anos, 2.282 pessoas sofreram ameaças de morte por questões relacionadas à terra. Destas, 382 eram mulheres. Das 338 vítimas fatais, 20 eram mulheres.

\section{DESTERRITORIALIDADE E VIOLENCIA: CONCEITOS E DEFINIÇÕES}

A modernidade ocidental somada a outras formas de dominação (colonialismo, capitalismo, projeto hegemônico de desenvolvimento, neoliberalismo, globalização hegemônica) alteram profundamente a relação da humanidade com o ambiente e as relações coletivas. Ao mesmo tempo, criam-se novas formas de dominação e reelaboram-se as já existentes.

O aparecimento do Estado é responsável pelo primeiro grande movimento de desterritorialização, na medida em que ele imprime a divisão da terra pela organização administrativa, fundiária e residencial. O Estado desterritorializa os agenciamentos maquínicos ${ }^{10}$ de corpos e os agenciamentos coletivos de enunciação e procede a uma sobre codificação, ou seja, ele opera por novos agenciamentos, tanto maquínicos como de enunciação. O Estado fixa o homem à terra, mas o faz de forma despótica, organiza os corpo e os enunciados de outras formas. ${ }^{11}$

\footnotetext{
${ }^{10}$ Em relação a máquina/maquínico ver GUATTARI, E e ROLNIK, S. Micropolítica: cartografias do desejo. Petrópolis: Vozes, 1986.

${ }^{11}$ Ver para esse tema obra de Deleuze e Guattari, através da obra O Anti-Édipo (publicado originalmente em 1972) e desdobrada sobretudo em Mil Platôs (1980) e O que é a filosofia?(1991).
} 
Deleuze e Guattari (1992) afirmam que a desterritorialização relativa diz respeito ao próprio socius. Isto significa dizer que a vida é um constante movimento de desterritorialização e reterritorialização, ou seja, estamos sempre passando de um território para outro, abandonando territórios, fundando novos. A escala espacial e a temporalidade é que são distintas.

O processo de desterritorialização acompanha a trajetória das comunidades indígenas na América Latina e também no Brasil. Induzindo as pessoas a se ver como indivíduos e não como coletividade incentiva-se ao desequilíbrio dos membros da comunidade que trazem em seu histórico a vida em grupo. Meneghel diz:

Os grupos que não interessam ao capital são eliminados e os corpos de "algumas mulheres" (indígenas, negras, pobres, migrantes, descartáveis) são alvo das políticas de terror. O capitalismo patriarcal, racista e colonial está promovendo uma guerra contra as mulheres, confirmada pelo aumento ascendente da violência femicida. (MENEGHEL; LERMA, 2016. P.119-120)

No contexto contemporâneo, sobretudo, brasileiro-latino-americano, observa-se que as territorialidades dos chamados povos ou comunidades tradicionais se reinventam constantemente tornando-se, também, nesse jogo interno e externo, cada vez mais múltiplas e fragmentadas em suas desterritorializações, conflitos, estratégias e disputas dentro do/com o Estado confluindo para a violência.

Habermas (1997) ${ }^{12}$ afirma que a violência equivale sempre a agressão física, portanto exterior ao simbólico. Contudo, essa crítica, além de restringir a violência apenas à dimensão física, ignora a possibilidade de as crenças dominantes imporem valores, hábitos e comportamentos sem recorrer necessariamente à agressão física, criando situações onde o indivíduo que sofre a violência simbólica sinta-se inferiorizado como acontece, por exemplo, nas questões que envolvem gênero, sexualidade, religião, dentre outras. Sabe-se que através das diversas formas e conceitos de diferentes pensadores no que tange o tema desterritorialização, é possível analisarmos o quão é relevante e quais as consequências que esse processo interefere na construção identitária. ${ }^{13}$

\footnotetext{
${ }^{12}$ Vide em Direito e democracia: entre facticidade e validade, volume I. Rio de Janeiro: Tempo Brasileiro, 1997.

${ }^{13}$ Para Habermas quanto mais complexa for a sociedade, maior será a racionalização a que se vê obrigado o seu mundo da vida. Também acredita que a história das sociedades modernas é a história de um processo de intensa racionalização do mundo da vida de sociedades tradicionais.
} 
A relação que se estabelece entre desterritorialização e violência, já foi assunto e tema de estudos de inúmeras vertentes de pesquisa. Antropólogos, filósofos, juristas, historiadores, sociólogos, dentre outros buscaram responder os motivos do processo de aculturação, assimilação, exclusão, extermínio, violência, dentre outros. Todavia, ainda que o tema em questão não seja novidade no cotidiano das sociedades, atualmente busca-se de forma incansável ressignificar conceitos, olhares analíticos, teorias e processos de empoderamento para compreender a complexidade da teia social global.

Os processos de empoderamento das mulheres indígenas são fundamentais para enfrentar as situações de violência, resgatando as práticas e crenças que estas consideram positivas e desafiando aquelas que consideram daninhas. A esse respeito, registram-se na região várias experiências nesta lógica, como a das Casas da Mulher, no México, que constitui um modelo de atenção à saúde e violência contra as mulheres e opera em 12 estados do país. Também o empoderamento das mulheres indígenas contribui à incidência política neste âmbito, como demonstram os casos do Equador, onde a reestruturação do sistema de administração da justiça inclui em suas prioridades a agenda da organização de mulheres indígenas; no Estado Plurinacional da Bolívia as mulheres indígenas conseguiram acordos para sua participação nos comitês municipais de supervisão da justiça; na fronteira entre o Brasil e o Paraguai as mulheres e crianças indígenas foram habilitadas para registrar e denunciar os casos de violação de seus direitos, inclusive o tráfico. Estas experiências contaram com um apoio significativo e sistemático das Nações Unidas, através dos organismos correspondentes; portanto, é fundamental que este apoio continue e seja reforçado para poder consolidar os avanços. (CEPAL, 2014. p. 93)

Nesse contexto, é importante enfatizar que é de extrema necessidade que os Estados adotem as medidas pontuais, em conjunto com os povos indígenas, para garantir que mulheres, crianças, adolescentes e jovens indígenas gozem de proteção e garantias plenas contra todas as formas de violência e discriminação. Adquire singular relevância o combate à violência de gênero associada também aos problemas de saúde mental que afetam particularmente os adolescentes e jovens, tanto nos territórios afetados pela pobreza e marginalização nos centros urbanos.

Nesse aspecto, é fundamental que a cooperação internacional renove seus compromissos e continue apoiando os governos e povos indígenas em suas iniciativas em 
particular, no contexto de discriminação e empobrecimento dos povos indígenas, que ainda não foi superado na América Latina.

\section{CONCLUSÃO}

$\mathrm{Na}$ tríade investigativa, comunidades indígenas, mulher e violência foi possível observar que independentemente do tempo a temática permanece atual. A culminação de um processo que iniciou no século XV com a constituição da América e do capitalismo colonial atrelado à ideia de poder permite compreender a gênese da violência emprenhada sobre as comunidades indígenas da América Latina. Dos diversos elementos sabe-se que ainda há muito que se avançar no processo de não violência as mulheres indígenas. Sabe-se que a ideologia de que o corpo das indígenas é violentável fica evidente quando se constata que há centenas de mulheres indígenas desaparecidas e mortas no Brasil e América

Muitas mortes vêm precedidas de mutilação, estupro e tortura. As mulheres pobres e as indígenas, em particular, têm sido o alvo. O processo de ocupação e colonização da América trouxe em si o ideário da diferença, do exotismo e dominação. Esse fato, e muitos outros, como as violências da assimilação forçada que descaracterizaram muitas comunidades, demonstram como os povos indígenas, a sociodiversidade e a formação pluriétnica da sociedade latino-americana e em especial a brasileira foram singularmente abordadas ao longo da história. Inicialmente se desencadeou o ocultamento da diversidade, posterior a regulação jurídica inicial, marcada pelo viés da invisibilidade e da negação de direitos, seguida dos processos de aculturação e assimilação - razão de uma persistente racionalidade colonialista que resulta por diversas ocasiões em confrontos diretos ao direito e à justiça, além do detrimento de toda a riqueza cultural própria.

Além disso, o diálogo pluricultural nem sempre trouxe respostas, já que em muitas análises desconsiderou-se o reconhecimento dos sistemas de saberes, cosmovisão e conceitos de cotidianidade dos povos indígenas, em particular das mulheres, adolescentes e jovens nativas. Os programas ou iniciativas estatais de erradicação da violência, além de não garantir a participação das organizações de mulheres indígenas em todas as etapas do processo, requerem a abertura de espaços de reflexão dessas mulheres sobre a conceitualização da violência e suas manifestações, segundo as suas necessidades. Geralmente as crianças e jovens indígenas também não são ouvidos, para saber o que pensam e como vivem a violência. 
Já os processos de empoderamento das mulheres indígenas continuam sendo essenciais para enfrentar as situações de violência, resgatando as práticas e crenças que elas consideram positivas reforçando seus contexto identitário e cidadão.

\section{REFERÊNCIAS BIBLIOGRÁFICAS}

ANAYA, S. James. Los pueblos indígenas em el derecho internacional. Tradução de Luis Rodrigues-Piñero Royo; Pablo Gutierrez Veja; Bartolomé Clavero. New York, USA. Ed.Trota, 2005.

BOURDIEU, Pierre. O Poder Simbólico. Rio de Janeiro: Bertrand Brasil, 1992.

BRIGHENTI, Clovis A. O "desenvolvimento" versus os povos indígenas. In: CIMI. Relatório: Violência contra os povos indígenas no Brasil. Dados 2014. Brasília: Cimi, 2015.

Colonialidade do poder e a violência contra os povos indígenas. In: Revista PerCursos. Florianópolis, v. 16, n.32, p. 103-120, set./dez. 2015.

CASTELLS, Manuel. Redes de indignação e esperança: movimentos sociais na era da internet. Tradução Carlos Alberto Medeiros. Rio de Janeiro: Zahar, 2013.

CASTRO-GOMEZ, Santiago; GOSFROGUEL, Ramón (Comp). El giro decolonial: reflexiones para una diversidad epistémica más allá del capitalismo global. Bogotá: Universidad Javeriana-Instituto Pensar, Universidad Central-IESCO, Siglo del Hombre, 2007. P. 127-167.

COMPARATO, Fábio Konder. A afirmação histórica dos direitos humanos. 7. ed. São Paulo: Saraiva, 2010.

DELEUZE, G. Conversações. Rio de Janeiro: Editora 34, 1992.

DELEUZE, G. e GUATTARI, F. O Anti-Édipo: capitalismo e esquizofrenia. Lisboa: Assírio \& Alvim. s/d. [ed. original: 1972].

O que é a Filosofia? Rio de Janeiro: Ed. 34. 1992.

Mil Platôs: capitalismo e esquizofrenia. Vol.1. Rio de Janeiro: Ed. 34, 1995a. .Mil Platôs: capitalismo e esquizofrenia. Vol. 2. Rio de Janeiro: Ed. 34, 1995b. Mil Platôs: capitalismo e esquizofrenia. Vol. 3. Rio de Janeiro: Ed. 34, 1996. .Mil Platôs: capitalismo e esquizofrenia. Vol. 5. Rio de Janeiro: Ed. 34, $1997 .$. 
GUHA, Ranajit. Dominance without hegemony: history and power in colonial india. Cambridge: Cambridge University Press, 1997.

HABERMAS, Jürgen. Direito e democracia: entre facticidade e validade. Vol. I. Rio de Janeiro: Tempo Brasileiro, 1997.

HALSEY, Theresa; JAIMES, Annette M. American Indian Women: At the Center of Indigenous Resistance in North America. In: State of Native America, ed. M. Annette Jaimes: Boston, South End Press, 1992.

LANDER, Edgardo. Marxismo, eurocentrismo y colonialismo. In: BORON, Atilio; AMADEO, Javier; GONZÁLEZ, Sabrina (Comp.). La teoría marxista hoy: problemas y perspectivas, Buenos Aires: CLACSO, 2006.

LINERA, Alvaro Garcia. A Potência Plebéia: ação coletiva e identidades indígenas, operárias e populares na Bolívia. São Paulo: Boitempo, 2010.

PEREIRA, Ana Cristina Paulo. A proteção patentária interna e internacional: implicações do Acordo TRIPS/OMC na ordem jurídica brasileira. Rio de Janeiro: Lumen Juris, 2009.

QUIJANO, Aníbal. Colonialidad del poder, eurocentrismo y América Latina. In: La colonialidad del saber: eurocentrismo y ciencias sociales. Perspectivas Latinoamericanas. Edgardo Lander (comp.) CLACSO, Consejo Latinoamericano de Ciencias Sociales, Buenos Aires, Argentina, 2000.

SANTILLI, Juliana. Socioambientalismo e novos direitos: proteção jurídica à diversidade biológica e cultural. São Paulo: Peirópolis, 2005.

SOUSA SANTOS, Boaventura. La globalización del derecho: los nuevos caminos de la regulación y la emacipación. Bogotá: Universidad Nacional de Colômbia/ILSA-Instituto Latinoamericano de Servicios Legales Alternativos, 1998.

ZAFFARONI, E. Raúl. El Derecho latinoamericano en la fase superior del Colonialismo. In: Revista Pensar en derecho. FERREYRA, Raúl Gustavo. El principio de subordinación como fundamento del Estado constitucional. Su regulación en Argentina, Brasil, Colombia, Ecuador y México, 2014.

ZAMBRANO ESCOVAR, Marta. Trabajadores, villanos y amantes: encuentros entre indígenas y españoles en la ciudad letrada. Santa Fe de Bogotá (1550-1650). Bogotá: Instituto Colombiano de Antropologia e Historia, 2008.

WEBER, Max. Economía y sociedad: esbozo de sociología compreensiva. Fondo de Cultura Económica-Sección de obras de sociología, 1964. 


\section{FONTES ELETRÔNICAS}

ALDAO, M. M y CLÉRICO, L., Nuevas miradas de la igualdad en la jurisprudencia de la Corte Interamericana de Derechos Humanos: la igualdad como redistribución y como reconocimiento. In: Estudios Constitucionales, vol. 9, $\mathrm{n}^{\circ} 1$, Centro de Estudios Constitucionales, $\quad$ Santiago, 2011. Disponível em: http://www.scielo.cl/pdf/estconst/v9n1/art06.pdf. Acesso em: 04 de abril de 2017.

Comissão Econômica para a América Latina e Caribe (CEPAL/ONU). Los pueblos indígenas en América Latina. Avances en el último decenio y retos pendientes para la garantía de sus derechos. Síntesis. Chile: Imprensa Oficial, 2015. Disponível em http://www.cepal.org/es/publicaciones. Acesso em 20 de março de 2017.

Comissão Pastoral da Terra (CPPT/Brasil). Centro de Documentação - Dados e Notas. Disponível em: https://cptnacional.org.br. Acesso em: 03 de abril de 2017.

Convenção sobre Diversidade Biológica (ABS). In: Conhecimento Tradicionais. Trad. Carlos Potiara Castro. Montreal, 2012. Disponível em: https://www.cbd.int/abs/infokit/revised. Acesso em 25 de março de 2017.

CLÉRICO, Laura. Las otras caras de los derechos sociales: las obligaciones iusfiindamentales y la desigualdad estructural. In: A.A.V.V La Corte y los derechos 2005/2007. Buenos Aires, SXXI/ADC, p. 478-494. Acesso em 25 de março de 2017.

Movimento de Atingidos pelas Barragem (MAB). Relatório da Comissão Especial das Barragens. In: Conselho de Defesa dos Direitos da Pessoa Humana (CDDPH). Brasília, 2010. Disponível em: http://www.sdh.gov.br. Acesso em 25 de março de 2017.

Organização das Nações Unidas (ONU). Relatório da $1^{\text {a }}$ Conferência Mundial sobre os Povos Indígenas. Nova Iorque, 2014. Disponível em http://www.onu.org.br. Acesso em: 03 de abril de 2017.

. Las tecnologías de la información y las comunicaciones para el desarrollo. Declaração das Nações Unidas sobre os Direitos dos Povos Indígenas (A/RES/61/295), 2007. Disponível em http://www.un.org/es/comun/docs. Acesso em 13 de mar. 2017. 
Publicações ONU Mulheres Brasil. Disponível em:

http://www.onumulheres.org.br. Acesso em: 04 de abr. 2017.

Organização Internacional do Trabalho (OIT). Convenio 169. Disponível em: http://www.ilo.org/indigenous/Conventions/no169/. Acesso em 10 de mar. 2017.

MENEGHEL, Stela; LERMA, Betty Ruth Lozzano. Feminicídios em grupos étnicos e racializados: síntese. In: Revista Opinião. Disponível em: http://www.scielo.br/pdf/csc/v22n1/1413-8123-csc-22-01-0117.pdf. Acesso em: 30 de março de 2017.

VILELA, Ana Laura Silva. A dimensão colonial da cidadania na América Latina: aportes epistemológicos. In: Sociologia, Antropologia e Cultura Jurídica/CONPEDI. Florianópolis: Ed. Conpedi, Florianópolis, 2015. Disponível em: www.conpedi.org. Acesso em: 02 de abr. 2017.

WALSH, Catherine. Interculturalidad, Estado, Sociedad: Luchas (de)coloniales de nuestra época. Quito: Universidad Andina Simón Bolivar, Ediciones Abya-Yala, 2009. Disponível em: http://www.flacsoandes.edu.ec/interculturalidad/wpcontent/uploads/2012/01/Interculturalidad-estado-y-sociedad.pdf. Acesso em: 15 de março de 2017. 